\title{
Injuries and helmet use related to non-motorized wheeled activities among pediatric patients
}

\author{
H. Lindsay, MD (1, 2); M. Brussoni, PhD (2, 3, 4, 5, 6)
}

This article has been peer reviewed.

\begin{abstract}
Introduction: Patients presenting to emergency departments (ED) for injuries resulting from recreational activities represent a unique source of information on important directions for injury prevention efforts. We describe the epidemiology of non-motorized wheeled activity-related injury in pediatric patients presenting to Canadian EDs as well as patients' helmet use.
\end{abstract}

Methods: Data for the years 2004 to 2009 were abstracted from the Canadian Hospitals Injury Reporting and Prevention Program (CHIRPP), a national ED injury surveillance program in fifteen hospitals.

Results: Most of the 28618 children aged 1 to 16 years injured during non-motorized wheeled activities were injured while cycling, followed by skateboarding. Most injuries occurred among boys. Children injured on scooters tended to be younger whereas skateboarders were the oldest. On average, the number of all injuries decreased by $6 \%$ over the time period. Falls were the most common mechanism of injury; $8.3 \%$ of patients had head injuries, which were seen more often among cyclists than other wheeled-activity users. Helmet use was greatest among cyclists $(62.2 \%)$ and lowest among skateboarders (32.9\%). Injured patients presenting to EDs in jurisdictions with legislation mandating helmet use had 2.12 greater odds of helmet use and 0.86 lesser odds of head injury compared with those presenting in jurisdictions without helmet laws.

Conclusion: These results provide further evidence that legislation mandating helmet use may be an effective way of reducing injury among all wheeled-activity users. The small number of patients who presented with helmet use and protective gear $(59.4 \%$ overall) suggests that this remains an area for intervention.

Keywords: child, bicycling, in-line skating, skateboarding, scooters, helmet use

\section{Introduction}

Non-motorized wheeled activities result in significant injury-related morbidity and mortality in children. ${ }^{1,2}$ According to the National Trauma Registry, 27589 people were hospitalized in Canada due to injuries secondary to wheeled activities between
2004 and 2009, and 22023 of these hospitalizations were among cyclists. $^{2}$ However, these numbers represent only admissions to hospital, and fail to account for the full impact to the health care system, as many injuries are treated in emergency departments (ED) or on an outpatient basis (i.e. fractures and minor head injuries).
Several studies comparing injury patterns in different wheeled activities have demonstrated differences based on age distribution..$^{3-5}$ Previous studies have suggested that, while cyclists suffer a greater number of fractures due to the popularity of cycling, the proportion of fractures is greater with the use of other nonmotorized wheeled devices. ${ }^{6}$ Fracture rates among injured pediatric cyclists presenting to Canadian EDs have ranged from $26.3 \%$ to $28.9 \%,{ }^{7,8}$ whereas a Norwegian study that looked at small-wheeled devices reported that $69 \%$ of in-line skaters, $48 \%$ of skateboarders and $49 \%$ of scooter users presented with fractures. ${ }^{3}$ Similarly, Canadian data demonstrated fracture rates of $36.6 \%$ to $48.1 \%$ among users of smallwheeled devices. ${ }^{8}$

Previous studies have used ED injury surveillance data from the Canadian Hospitals Injury Reporting and Prevention Program (CHIRPP) to outline injury patterns in Canada among cyclists ${ }^{7}$ and in-line skaters. ${ }^{9}$ Hospitalization data from a 2002 Canadian study suggested that there have been decreases in severe injuries from cycling since the widespread implementation of helmet laws. ${ }^{10}$ However, with the exception of one 2009 study that used Alberta Children's Hospital CHIRPP data to examine injuries from wheeled shoes and compare injury patterns and helmet use across other wheeled activities, few studies have compared injury patterns or helmet use in different wheeled activities. ${ }^{6}$ Thakore et al. ${ }^{6}$ found injuries to the head and face in $15 \%$ to $22 \%$ of users regardless of the type of wheeled activity; they also

\section{Author references:}

1. Faculty of Medicine, University of Toronto, Toronto, Ontario, Canada

2. School of Population and Public Health, University of British Columbia, Vancouver, British Columbia, Canada

3. Department of Pediatrics, University of British Columbia, Vancouver, British Columbia, Canada

4. British Columbia Injury Research \& Prevention Unit, Vancouver, British Columbia, Canada

5. Child \& Family Research Institute, Vancouver, British Columbia, Canada

6. British Columbia Children's Hospital, Vancouver, British Columbia, Canada

Correspondence: Mariana Brussoni, F511-4480 Oak Street, Vancouver, BC V6H 3V4; Tel.: 604-875-3712; Fax: 604-875-3569; Email: mbrussoni@cw.bc.ca 
found that fractures were, in fact, more common among non-cyclists in Alberta.

The aim of our current study is to analyze CHIRPP ED surveillance data to describe the epidemiology of injury related to nonmotorized wheeled activity as well as helmet use in pediatric patients presenting to EDs, and to determine if helmet use varies based on regional legislation. Examining Canada-wide ED data and outlining the types of injuries with which users of these devices are presenting can help target injury prevention strategies. Administrative data sets, such as discharge abstract data, capture only a fraction of injury cases because the majority of injured children, particularly those with less severe injuries, are not admitted to hospital. Further, these data sets neither describe injury events nor record use of safety equipment, while CHIRPP ED surveillance data permit such levels of analyses.

\section{Methods}

Data on patients with injuries caused by all wheeled, non-motorized devices were abstracted from CHIRPP for the years 2004 to 2009. CHIRPP is a national ED surveillance program that registers injury cases from 11 pediatric and 4 general Canadian hospital EDs in the following municipalities: Vancouver (B.C.), Calgary (Alta.), Edmonton (Alta.), Winnipeg (Man.), London (Ont.), Kingston (2; Ont.), Ottawa (Ont.), Montréal (2; Que.), Québec (Que), Toronto (Ont.), Halifax (N.S.), St. John's (N.L.) and Arctic Bay (Nvt.). ${ }^{11}$ Any patient or caregiver presenting with an injury is asked to voluntarily complete a form about the injury event. If the patient or their proxy is unable to complete the form, a staff member fills in the report based on interviews or from the patient's chart. Questions on the form describe the circumstances surrounding the injury, including the factors causing or contributing to the injury and the time and place of the injury event. Medical diagnostic information is coded by a local CHIRPP coordinator. ${ }^{11}$ The collated injury reporting forms are sent to the national CHIRPP centre at the Public Health Agency of Canada, where they are coded by a trained data support officer.
Our analyses included pediatric patients presenting to any CHIRPP hospital. As a majority of the CHIRPP hospitals are pediatric centres, and many of them only treat patients aged up to 17 years, we included only patients aged between 1 and 16 years (12 to 203 months), inclusive. A number of variables in CHIRPP ensure complete capture of all cases of nonmotorized wheeled activities. These include "activity at the time of injury" (Context), "factor codes" and "narrative fields" (Injury Event Description and Product). Cases were included if (1) the activity at the time of injury was coded as bicycling (including unicycles and tricycles), skateboarding, in-line skating/ rollerblading or using a scooter; or (2) any of the six CHIRPP factor code fields contained a value for any one of the four non-motorized wheeled devices (bicycle, skateboard, scooter or in-line skates/roller blades); or (3) the narrative fields contained any of a number of text strings (French and English) related to the four activities/devices. Different types of each device were included; unicycles and tricycles were counted as bicycles and no distinction was made between roller skates and in-line skates. After receiving the coded data from the national CHIRPP centre, each narrative text string in the data set was examined. If the narrative text indicated that the injury did not take place during use of a wheeled device or that the device in question was either motorized or a stroller, the record was excluded. Use of helmet was defined by the patient or caregiver checking "helmet" on the CHIRPP form that asks if any safety equipment was being worn when the injury occurred. Protective gear was considered as being used if any of the others options were checked on the same question ("sports padding," "mouthguard," etc). Study methods were approved by the Children's and Women's Hospital of British Columbia Research Ethics Board.

Of the eight provinces represented in CHIRPP, five had jurisdictional legislation mandating helmet use during the years covered in the analysis (either provincialwide legislation or municipal by-laws that encompass the location of the CHIRPP hospital, for example, St. John's in
Newfoundland). All enactments of bicycle helmet legislation took place prior to 2004, although Nova Scotia expanded their helmet laws to include all wheeled activities in 2007. ${ }^{12}$ Two provinces, British Columbia and Nova Scotia, mandated use at all ages, while use in Alberta and Ontario was limited to those aged under 18 years, and in St. John's (N.L.) to children under 12 years.

Comparisons were made between the four types of wheeled activities by median age and proportion of sex. Frequencies of injury patterns (as defined by the CHIRPP data set and indicated as present by the treating physician) were compared across activity type, including "fractures," "dislocations" and "head injury." Last, frequencies of helmet use and protective gear were compared across activity type. Data management and analyses were performed using Microsoft Excel (Microsoft Corp, 2010) and SPSS version 20.0 (IBM Corp, 2011). Odds ratios were used to demonstrate significant differences in frequencies, and were calculated by using binary logistic regression adjusting for age, sex and non-motorized wheeled activity, with 95\% confidence intervals (CIs) calculated. Generalized Poisson regression was used for time trends to quantify the relationship between year and the number of occurring injuries. To address the overdispersion issue in the count data, we used Pearson chi-square with $95 \%$ CI to estimate the scale parameter and obtain more conservative variance estimates and significance levels. ${ }^{13} \beta$ exponential estimates, which tell the relative change in the number of injuries by year, are derived from this regression model. The regression assumes that the denominator (number of people at risk of injury) did not alter over time.

\section{Results}

\section{Agé and sex demographics}

From 2004 to 2009, a total of 28618 injury patient records met the inclusion criteria, representing 28618 patients with 35184 injuries from non-motorized wheeled activities. Patients with cycling-related injuries accounted for $72.8 \%$ (20 838/28 618); skateboarding, $17.1 \%$ (4892/28 618); scooter- 
related events, $6.7 \%$ (1904/28 618); and in-line skating, 3.1\% (891/28 618).

Table 1 shows the sex and age distribution of injuries by the various non-motorized wheeled activities. Most injuries occurred among boys (74.1\%). All activities had a greater proportion of boys than of girls, with skateboarding having the largest male to female ratio (8.2), and scooter usage the smallest (1.4). Most children presenting with injuries from non-motorized wheeled activities were between 9 and 12 years old $(37.2 \%)$, but age distribution varied significantly by sport. Children presenting with scooter injuries were younger, with a median age of 9.4 years; cyclists were slightly older, with a median age of 10.9 years, in-line skaters had a median age of 11.7 years, and skateboarders tended to be the oldest, at a median of 13.3 years.

Time trends in injuries caused while doing a non-motorized wheeled activity

All non-motorized wheeled activities peaked in injury presentation during the summer months, with between $40 \%$ and $50 \%$ of presentations occurring in the July to September time period across all 6 years. Overall, the number of all-injury presentations as a result of non-motorized wheeled activities decreased significantly between 2004 and 2009 (Figure 1), on average by $6.0 \%$ annually $(\operatorname{ExpB}=0.94$; $95 \%$ CI: 0.92-0.96). All types of injury from non-motorized wheeled activities decreased significantly over the years, except injuries among scooter users $(\operatorname{ExpB}=1.00 ; 95 \%$ CI: 0.97-1.03). The number of cyclists presenting with injuries decreased on average about $5.1 \%$ $(\mathrm{ExpB}=0.95 ; 95 \%$ CI: 0.93-0.97), of skateboarders by $9.0 \%$ (skateboarders: $\operatorname{ExpB}=0.91 ; 95 \%$ CI: 0.86-0.96) and of in-line skaters by about $21.5 \%$ $(\operatorname{ExpB}=0.79 ; 95 \%$ CI: 0.69-0.90) every year.

\section{Injury patterns from non-motorized wheeled activities}

Mechanisms of injury from non-motorized wheeled activities were similar across activities, with falls the most common (82\%-91\%; data not shown). Collisions and motor vehicle collisions (MVCs) were the two other mechanisms that contributed most to injury. Cyclists presented with MVC as a mechanism of injury $5.9 \%$ of the time, while MVCs made up between $1.7 \%$ and $4.9 \%$ of injury presentations across other activities.
The most common types of injuries seen overall were superficial injuries and fractures, followed by musculoskeletal injuries such as sprains (Table 2). In-line skaters had the greatest proportion of fractures at $46.1 \%$. Severe injuries, particularly those classified as injuries to internal organs or neurovascular injuries or multiple, were most numerous among cyclists. Head injuries accounted for over $8.3 \%$ of injuries overall, and were most likely to be among cyclists. Skateboarders had the highest proportion of musculoskeletal injuries such as sprains, and children using scooters had the highest proportion of dental injuries.

The most common type of fracture was of the elbow and forearm across all activities, followed by wrist and hand fractures (Table 3). Skateboarding had the highest count and proportion of ankle and foot fractures.

\section{Helmet use and protective gear}

Among children presenting with injury from non-motorized wheeled activities, $55.3 \%$ reported using a helmet (excluding missing data; data not shown). The proportion of records by sex, presence of head injury, and admission where helmet

TABLE 1

Sex and age distribution by type of non-motorized wheeled activity, ages 1-16 years, 2004-2009

\begin{tabular}{|c|c|c|c|c|c|c|c|c|c|c|}
\hline \multirow[t]{2}{*}{ Sex ${ }^{a}$, age (years) ${ }^{b}$} & \multicolumn{2}{|c|}{ Bicycle } & \multicolumn{2}{|c|}{ Skateboard } & \multicolumn{2}{|c|}{ Scooter } & \multicolumn{2}{|c|}{ In-line skates } & \multicolumn{2}{|c|}{ Total } \\
\hline & $\mathbf{n}$ & $\%$ & $\mathbf{n}$ & $\%$ & $\mathbf{n}$ & $\%$ & $\mathbf{n}$ & $\%$ & $\mathbf{n}$ & $\%$ \\
\hline \multicolumn{11}{|l|}{ Male } \\
\hline $1-4$ & 1269 & 6.1 & 61 & 1.2 & 139 & 7.3 & 9 & 1.0 & 1478 & 5.2 \\
\hline $5-8$ & 3375 & 16.2 & 289 & 5.8 & 368 & 19.3 & 86 & 9.7 & 4118 & 14.4 \\
\hline $9-12$ & 5206 & 25.0 & 1503 & 30.2 & 466 & 24.5 & 253 & 28.4 & 7428 & 26.0 \\
\hline $13-16$ & 5276 & 25.3 & 2587 & 51.9 & 136 & 7.1 & 182 & 20.4 & 8181 & 28.6 \\
\hline Subtotal & 15126 & 72.6 & 4440 & 89.1 & 1109 & 58.2 & 530 & 59.5 & 21205 & 74.1 \\
\hline \multicolumn{11}{|l|}{ Female } \\
\hline $1-4$ & 637 & 3.1 & 9 & 0.2 & 61 & 3.2 & 5 & 0.6 & 712 & 2.5 \\
\hline $5-8$ & 1847 & 8.9 & 71 & 1.4 & 272 & 14.3 & 64 & 7.2 & 2254 & 7.9 \\
\hline $9-12$ & 2341 & 11.2 & 258 & 5.2 & 405 & 21.3 & 221 & 24.8 & 3225 & 11.3 \\
\hline $13-16$ & 887 & 4.3 & 204 & 4.1 & 57 & 3.0 & 71 & 8.0 & 1219 & 4.3 \\
\hline Subtotal & 5712 & 27.4 & 542 & 10.9 & 795 & 41.8 & 361 & 40.5 & 7410 & 25.9 \\
\hline Total & $20838^{c}$ & 100.0 & $4982^{c}$ & 100.0 & 1904 & 100.0 & 891 & 100.0 & $28615^{c}$ & 100.0 \\
\hline
\end{tabular}

Abbreviation: df, degrees of freedom.

a Sex by activity: $\chi^{2}=959.2, \mathrm{df}=3, p<.001$.

b Age by activity: $\chi^{2}=2375.4, \mathrm{df}=9, p<.001$.

c Data on sex was missing for 3 patients, 1 for cyclists and 2 for skateboarders. 
FIGURE 1

Number of injury presentations by non-motorized wheeled activity, per year, 2004-2009, ages $1-16$ years

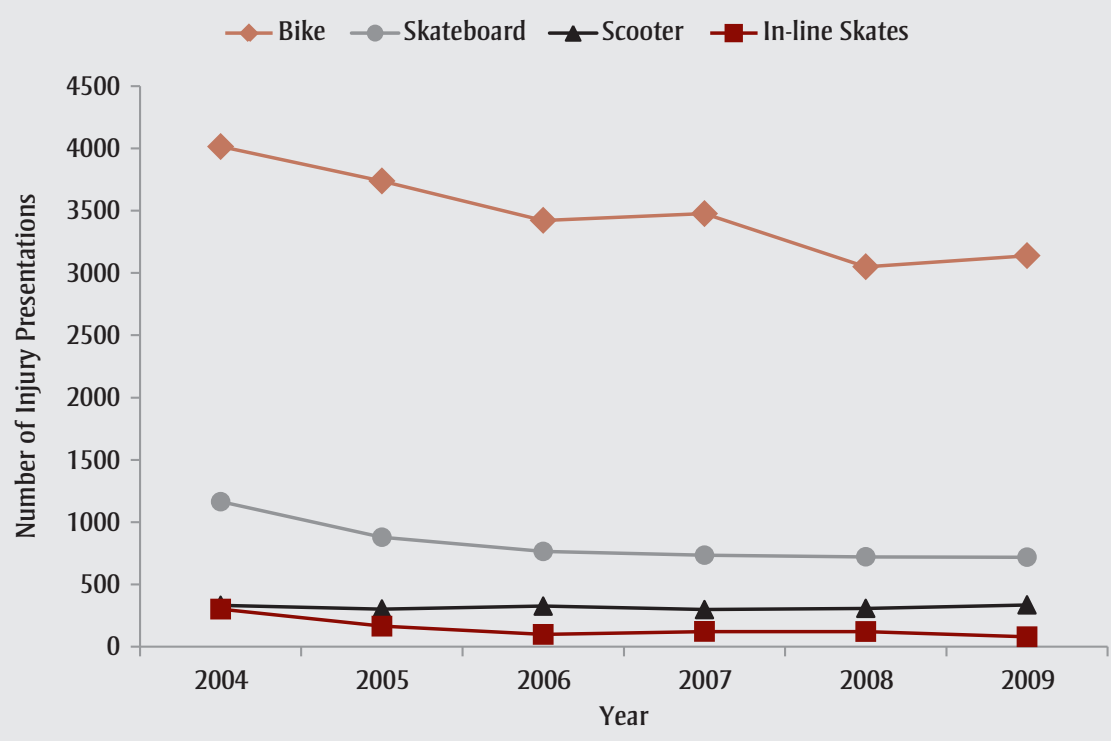

data were missing was similar (within $3 \%$ ) to that where helmet data were recorded. A higher proportion of 1 to 4 year olds $(12.3 \%$ vs. $6.0 \%)$ were represented in the records missing helmet data; cyclists were represented less $(68.8 \%$ vs. $74.3 \%)$ in the records missing helmet data.
Helmet use varied across non-motorized wheeled activities, with use being greatest among cyclists (62.2\%) and then among in-line skaters $(47.1 \%)$, scooter riders (39.7\%) and skateboarders (32.9\%). Other protective gear was used by only $4.1 \%$ of patients overall, and particularly among in-line skaters, at $12.7 \%$ of patients presenting. Across all activities and regardless of age or sex, children wearing helmets were less likely to experience a head injury compared with those not wearing a helmet (Table 4).

Among all the patients presenting with injuries from non-motorized wheeled activities, 2314 (8.1\%) were admitted to hospital. Of the patients for whom helmet data were available, admitted patients were significantly less likely to be wearing a helmet, regardless of age or sex, compared with patients who were discharged home. When analyzed by activity type, however, this difference was only significant for cyclists (Table 4).

\section{Helmet use and helmet legislation}

Patients presenting to the ED with an injury from non-motorized wheeled vehicles in jurisdictions where helmet use is mandated had significantly lesser odds (OR $=0.86$, 95\% CI: 0.80-0.94) of having sustained a head injury, regardless of age and sex (Table 5). There was also an association between legislation and helmet use, as patients presenting in legislated jurisdictions had 2.12 times greater

TABLE 2

Type of injury by non-motorized wheeled activity, ages 1-16 years, 2004-2009

\begin{tabular}{|c|c|c|c|c|c|c|}
\hline Injury type & $\begin{array}{c}\text { Bicycle } \\
\text { n (\%) }\end{array}$ & $\begin{array}{c}\text { Skateboard } \\
\text { n (\%) }\end{array}$ & $\begin{array}{l}\text { Scooter } \\
\text { n (\%) }\end{array}$ & $\begin{array}{c}\text { In-line skates } \\
\text { n (\%) }\end{array}$ & $\begin{array}{l}\text { Total }^{\mathrm{a}} \\
\text { n (\%) }\end{array}$ & $\chi^{2}(d f, p)^{b}$ \\
\hline Superficial injuries & $10036(38.0)$ & 974 (17.4) & $734(33.2)$ & $211(21.8)$ & $11955(34.0)$ & \\
\hline Fractures & $7446(28.2)$ & 2315 (41.5) & 766 (34.6) & $447(46.1)$ & 10974 (31.2) & $514.2(3,<.001)$ \\
\hline Musculoskeletal $^{c}$ & $4836(18.3)$ & 1765 (31.6) & $449(20.3)$ & $231(23.8)$ & $7281(20.7)$ & \\
\hline Head injury (minor) ${ }^{\mathrm{d}}$ & $2278(8.6)$ & $293(5.2)$ & $122(5.5)$ & $40(4.1)$ & $2733(7.8)$ & $110.1(3,<.001)$ \\
\hline Head injury (severe) ${ }^{\mathrm{e}}$ & $166(0.6)$ & $27(0.5)$ & $7(0.3)$ & $3(0.3)$ & $203(0.6)$ & $5.8(3,<.12)$ \\
\hline Multiple or severe injuries ${ }^{f}$ & $420(1.6)$ & $35(0.6)$ & $10(0.5)$ & $4(0.4)$ & 469 (1.3) & $53.6(3,<.001)$ \\
\hline Dislocations & $143(0.5)$ & $52(0.9)$ & $9(0.4)$ & $9(0.9)$ & $213(0.6)$ & \\
\hline Other ${ }^{g}$ & $395(1.5)$ & $73(1.3)$ & $37(1.7)$ & $20(2.1)$ & $525(1.5)$ & \\
\hline Total $^{\mathrm{a}}$ & $26421(100)$ & $5583(100)$ & $2211(100)$ & $969(100)$ & $35184(100)$ & \\
\hline
\end{tabular}

Abbreviation: df, degrees of freedom.

${ }^{a}$ Numbers represent total injury counts, patients may have more than one injury.

b $\chi^{2}$ compares proportions across activity types.

c Musculoskeletal injuries, e.g. sprains.

${ }^{\mathrm{d}}$ Minor head injuries include minor head injury and concussion.

e Severe head injuries include intracranial injuries.

${ }^{\mathrm{f}}$ Multiple or severe injuries include traumatic amputation, injury to internal organ, crushing injury, multiple injuries of more than one nature, injury to blood vessels and to nerves.

8 Other injuries include injuries to the eye, respiratory tract, alimentary tract and soft tissue; burns or corrosions; and unspecified injuries. 
TABLE 3

Type of fracture by non-motorized wheeled activity, ages 1-16 years, 2004-2009

\begin{tabular}{|c|c|c|c|c|c|c|}
\hline Type of fracture & $\begin{array}{c}\text { Bicycle } \\
\text { n (\%) }\end{array}$ & $\begin{array}{c}\text { Skateboard } \\
\text { n (\%) }\end{array}$ & $\begin{array}{l}\text { Scooter } \\
\text { n (\%) }\end{array}$ & $\begin{array}{c}\text { In-line skates } \\
\text { n (\%) }\end{array}$ & $\begin{array}{l}\text { Total }^{\mathbf{a}} \\
\text { n (\%) }\end{array}$ & $\chi^{2}(d f, p)^{b}$ \\
\hline Elbow and forearm & $3288(44.2)$ & $806(34.8)$ & $335(43.7)$ & $212(47.4)$ & $4641(42.3)$ & \\
\hline Wrist and hand & $1860(25.0)$ & $695(30.0)$ & $251(32.8)$ & $175(39.1)$ & $2981(27.2)$ & $301.7(3,<.001)$ \\
\hline Clavicle, shoulder and upper arm & 941 (12.6) & $130(5.6)$ & $37(4.8)$ & $23(5.1)$ & $1131(10.3)$ & \\
\hline Hip and leg & $562(7.5)$ & $200(8.6)$ & $70(9.1)$ & $21(4.7)$ & $853(7.8)$ & \\
\hline Ankle and foot & $351(4.7)$ & $441(19.0)$ & $57(7.4)$ & $11(2.5)$ & $860(7.8)$ & $862.3(3,<.001)$ \\
\hline Head and face & $338(4.5)$ & $37(1.6)$ & $15(2.0)$ & $3(0.7)$ & 393 (3.6) & \\
\hline Neck and spine & $53(0.7)$ & $3(0.1)$ & $1(0.1)$ & $1(0.2)$ & $58(0.5)$ & \\
\hline Trunk and pelvis & $52(0.7)$ & $3(0.1)$ & $0(0.0)$ & $1(0.2)$ & $56(0.5)$ & \\
\hline Total $^{\mathrm{a}}$ & $7445(100.0)$ & $2315(100.0)$ & 766 (100.0) & $447(100.0)$ & 10973 (100.0) & \\
\hline
\end{tabular}

Abbreviation: df, degrees of freedom.

Note: Data on type of injury was missing for 1 cyclist.

${ }^{a}$ Numbers represent injury counts, patients may have more than one injury.

b $\chi^{2}$ compares proportions across activity types.

odds of reporting helmet use $(95 \% \mathrm{CI}$ : 1.99-2.26).

\section{Discussion}

To our knowledge, this is the first epidemiological study that used Canada-wide data to compare injuries among users of non-motorized wheeled devices. It indicates that these injuries represent a significant proportion of the morbidity and ED use among pediatric patients and provides compelling evidence for the importance of helmet legislation for injury prevention.
Cycling accounted for most injuries, possibly as a result of its popularity: one Canadian survey found that $94 \%$ of children aged 5 to 12 years and $79 \%$ of children aged 13 to 17 years had ridden a bicycle in the previous 12 months. ${ }^{14}$ In an annual survey done in the United States, $39.8 \%$ of all participants aged over 7 years reported bicycling, $7.7 \%$ skateboarding, $7.5 \%$ in-line skating and $7.4 \%$ using a scooter. ${ }^{15}$ The same data showed that males made up $76 \%$ of skateboarders, $51 \%$ of in-line skaters, $56 \%$ of cyclists and $58 \%$ of scooter users. ${ }^{16}$ However, they made up a disproportionate majority of those presenting with injury across all nonmotorized wheeled activities. This may be due to boys' greater participation in certain activities $^{17}$ and/or differences in risktaking behaviours. ${ }^{18}$ While little is reported on the ages of the users of the wheeled activities, most previous studies on injury patterns have demonstrated a similar pattern of age distribution. Patients presenting with scooter-related injuries tended to be younger, and those presenting with injuries from skateboarding tended to be older. ${ }^{3,6}$ However, studies including adult data suggest that skateboard and scooter use are more prevalent in children. ${ }^{1,15}$ Almost

TABLE 4

Type of injury by non-motorized wheeled activity and helmet use, ages 1-16 years, 2004-2009

\begin{tabular}{|c|c|c|c|c|c|c|}
\hline \multirow[t]{2}{*}{ Activity } & \multicolumn{3}{|c|}{ Head injury } & \multicolumn{3}{|c|}{ Admission } \\
\hline & $\begin{array}{c}\text { Helmet }^{\mathrm{a}} \text { use } \\
\text { n (\%) }\end{array}$ & $\begin{array}{c}\text { No helmet use } \\
\text { n (\%) }\end{array}$ & $\begin{array}{c}\text { Adjusted }^{\mathrm{b}} \text { OR } \\
(95 \% \mathrm{Cl})\end{array}$ & $\begin{array}{c}\text { Helmet use } \\
\text { n (\%) }\end{array}$ & $\begin{array}{c}\text { No helmet use } \\
\text { n (\%) }\end{array}$ & $\begin{array}{c}\text { Adjusted }^{\mathbf{b}} \text { OR } \\
(95 \% \mathrm{Cl})\end{array}$ \\
\hline Bicycle & $887(46.1)$ & 1035 (53.9) & $0.43(0.39-0.47)$ & $687(54.1)$ & $583(45.9)$ & $0.63(0.56-0.71)$ \\
\hline Skateboard & 39 (16.5) & $198(83.5)$ & $0.33(0.23-0.46)$ & $56(29.9)$ & $131(70.1)$ & $0.78(0.56-1.07)$ \\
\hline Scooter & $24(27.6)$ & $63(72.4)$ & $0.53(0.33-0.86)$ & $18(40.0)$ & $27(60.0)$ & $0.99(0.55-1.85)$ \\
\hline In-line Skates & $8(29.6)$ & $19(70.4)$ & $0.33(0.14-0.79)$ & $6(35.3)$ & $11(64.7)$ & $0.51(0.18-1.41)$ \\
\hline Total & $958(42.1)$ & 1315 (57.9) & $0.49(0.45-0.54)$ & $767(50.5)$ & $752(49.5)$ & $0.74(0.67-0.83)$ \\
\hline
\end{tabular}

Abbreviations: $\mathrm{Cl}$, confidence interval; df, degrees of freedom; OR, odds ratio.

a Helmet use by activity: $\chi^{2}=1185.3, d f=3, p<.001$.

${ }^{\mathrm{b}}$ OR adjusted for age and sex. 
TABLE 5

Helmet use and head injury from non-motorized wheeled activity by helmet legislation, ages 1-16 years, 2004-2009

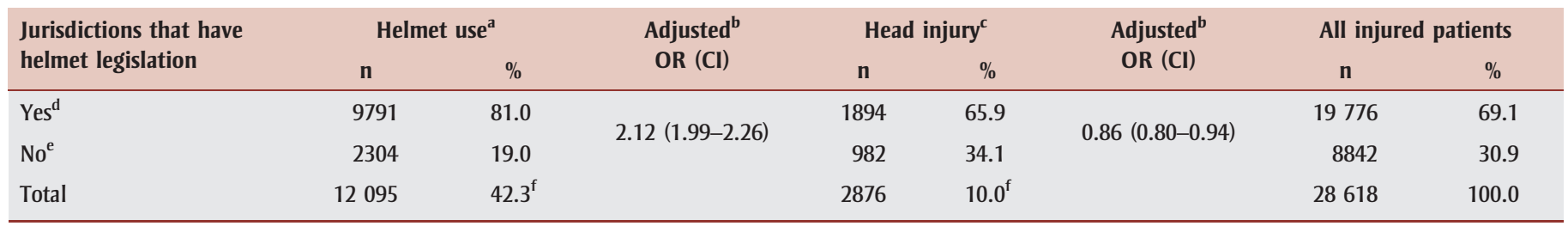

Abbreviations: $\mathrm{Cl}$, confidence interval; df, degrees of freedom; OR, odds ratio.

${ }^{\text {a }}$ Helmet use by legislation: $\chi^{2}=491.6, d f=1, p<.001$, data on helmet use excluded patients with no data for helmet use.

b OR adjusted for age, sex and non-motorized wheeled activity.

c Head injury by province: $\chi^{2}=15.6, \mathrm{df}=1, p<.001$.

d Jurisdictions with legislation: British Columbia, Alberta, Ontario, Nova Scotia, and St. John's (Newfoundland and Labrador).

e Jurisdictions without legislation: Nunavut, Manitoba, Quebec.

f Percentage of the total of injured patients.

all studies demonstrate that the majority of injury presentations from nonmotorized wheeled activities occur among those aged between 9 and 14 years. ${ }^{3,6,19}$ The decrease seen in injury presentations among cyclists may be due to a decrease in use over the same time period ${ }^{20}$ or may be due to successful injury prevention efforts.

Falls far exceeded other mechanisms of injury regardless of activity type. MVCs represented a very small portion, even for bicycle-related injuries, although due to the tendency for severe injuries to bypass the ED, these may not be well represented in CHIRPP. In any case, our findings suggest that, while traffic navigation skills are important in keeping children safe, the use of helmets and other safety gear that protect children when they do fall are justified, as are engineering strategies that reduce the likelihood of falls. Evidence shows that wrist guards, elbow pads and knee pads can protect against certain injuries, specifically wrist and forearm fractures, elbow injuries and knee injuries. $^{21,22}$ The most common injuries seen in our study across all activities were fractures, with elbow and forearm fractures predominating, and then wrist and hand fractures; such a pattern corresponds with findings from other research. ${ }^{6}$ This suggests that many of the injuries that wheeledactivity users experience could be prevented with the use of protective gear, which is in fact recommended by the American Association of Pediatrics. ${ }^{23}$ However, the overall use of protective gear was low across all activities, indicating an opportunity to intervene in an at-risk population.

Head injuries remain a significant cause of morbidity from non-motorized wheeled activities. Cyclists had the greatest proportion of head injuries, and in-line skaters the smallest. Fortunately, the rate of severe head injury remains low, although the proportion of severe head injury did not differ across activities, suggesting that the potential for severe head injury remains significant regardless of the type of nonmotorized wheeled activity. Further, as more is understood about sport-related concussion and head injury, ${ }^{24,25}$ patients presenting with even minor head injuries represent an opportunity to mitigate long-term consequences with appropriate education.

Our findings suggest that helmet use is associated with decreased likelihood of both head injury and admission. Further, the fact that hospitals in jurisdictions mandating helmet use had significantly higher proportion of helmet use and lower odds of head injury compared with those jurisdictions without helmet legislation suggests that legislation mandating helmet use increases helmet use and decreases the likelihood of head injury. Previous Canadian research has both demonstrated that helmet legislation reduces the rate of head injury in cyclists and that children's cycling rates increased after helmet legislation was introduced, suggesting that the protective effect of helmets is not the result of decreased cycling activity. ${ }^{10}$ As of
2010, six provinces had mandatory helmet legislation for cyclists under age 18 years, although enforcement may vary by region and is difficult to measure. ${ }^{12}$ The remaining seven provinces/territories have no legislation, although individual cities may have by-laws requiring the use of helmets, as is the case in St. John's (N.L.), where the CHIRPP hospital is located (although some of the patients presenting may have come from regions outside of the legislated area where helmet use is not mandated). Nova Scotia is the only province to enact a law requiring helmet use for all nonmotorized wheeled activities. ${ }^{12}$

Overall, helmet use in this study was only $55 \%$ (for cases with available data), which is comparable to rates calculated in a similar manner in other studies, ${ }^{6}$ including data reported by CHIRPP. ${ }^{8}$ It may be that children wearing helmets are less likely to be injured and therefore present to an $\mathrm{ED}$, or it may be related to how the information is collected at each hospital.

\section{Strengths and limitations}

As we were using retrospective data, our data and inferences are limited by how the forms were filled out by patients and physicians. The main limitation to this study was that we could not calculate rates of injuries for all users of non-motorized wheeled devices. The number of injuries seen is highly dependent on the frequency of use of each device and not representative of the incidence of injury from the activity. 
Further, patients presenting at CHIRPP hospitals may not be representative of all users of non-motorized wheeled activities. Most CHIRPP hospitals are found in urban settings and only represent a small number of total injuries presenting to healthcare. Patients presenting to other hospitals, walk-in clinics or family doctors are not captured. However, research suggests that CHIRPP data for sports and recreation activities in particular may be representative of the Canadian population. ${ }^{26,27}$ As well, using national data over a six-year period increased the statistical power of our data. The CHIRPP surveillance data represent the most extensive data source available from EDs across Canada, and are useful for describing the epidemiology of injured patients.

\section{Conclusion}

This study and other research support legislation mandating helmet use as an effective way of reducing injury in users of non-motorized wheeled activities. In addition, the ED may present a unique opportunity to prevent injury; past work has found that patients were receptive to information on preventing injury ${ }^{28}$ and more likely to modify behaviours after counselling in the ED. ${ }^{29}$ Studies have demonstrated that providing helmets or safety equipment such as booster seats, or having them conveniently available for purchase, increases reported use of safety devices. ${ }^{30,31}$ Children presenting to the ED with injuries may represent a significant opportunity to address and encourage safety recommendations.

\section{Acknowledgements}

Career support for Mariana Brussoni is provided by a Michael Smith Foundation for Health Research (MSFHR) scholar award and a British Columbia Child and Family Research Institute salary award. Data in this publication were used with the permission of the Public Health Agency of Canada. Our thanks to the Injury Section of the Health Surveillance and Epidemiology Division for their assistance in obtaining the data. The analyses and interpretations presented in this work do not necessarily reflect the opinions of the federal government. We also thank
Dr. Aybaniz Ibrahimova for assistance with data analyses.

\section{References}

1. Konkin DE, Garraway N, Hameed S, et al. Population-based analysis of severe injuries from motorized wheeled vehicles. Am J Surg. 2006;191:615-8.

2. Canadian Institute for Health Information. Cycling injury hospitalizations in Canada, 2009-2010. Ottawa (ON): CIHI; 2011.

3. Brudvik C. Injuries caused by small wheel devices. Prev Sci. 2006;7:313-20. doi:10.1007/ s11121-006-0031-8

4. Banas MP, Dalldorf PG, Marquardt JD. Skateboard and in-line skate fractures: a report of one summer's experience. J Orthop Trauma. 1992;6:301-5.

5. Zalavras C, Nikolopoulou G, Essin D, Manjra $\mathrm{N}$, Zionts LE. Pediatric fractures during skateboarding, roller skating, and scooter riding. Am J Sports Med. 2005;33:568-73. doi:10.1177/0363546504269256

6. Thakore S, Tram J, Hagel BE, Kyle T, Senger $\mathrm{T}$, Belanger $\mathrm{F}$. Injuries among wheeled shoe users: a comparison with other nonmotorized wheeled activities. Pediatr Child Health 2009;14:504-8.

7. Linn S, Smith D, Sheps S. Epidemiology of bicycle injury, head injury, and helmet use among children in British Columbia: a five year descriptive study. Inj Prev. 1998;4: 122-5.

8. Injury and Child Maltreatment Section. Emergency department surveillance injuries associated with wheeled, non-motorized devices: The Canadian Hospitals Injury Reporting and Prevention Program (CHIRPP), all ages, 1990-2007. Ottawa (ON): Public Health Agency of Canada; [modified 2011 Nov 8].

9. Ellis JA, Kierulf JC, Klassen TP. Injuries associated with in-line skating from the Canadian Hospitals Injury Reporting and Prevention Program database. Can J Public Health. 1995;86:133-6.
10. Macpherson AK, To TM, Macarthur C, Chipman ML, Wright JG, Parkin PC. Impact of mandatory helmet legislation on bicycle-related head injuries in children: a population-based study. Pediatrics 2002;110: e60-e60. doi:10.1542/peds.110.5.e60

11. Mackenzie SG, Pless IB. CHIRPP: Canada's principal injury surveillance program. Inj Prev. 1999;5:208-13.

12. ThinkFirst. Snapshot of bicycle helmet legislation [Internet]. ThinkFirst; 2010 [cited 2013 Apr 16]. Available from: http://www.thinkfirst .ca/documents/Snapshotofhelmetlegislation .pdf

13. McCullagh P, Nelder JA. Generalized linear models. 2nd ed. London (UK): Chapman \& Hall; 1989.

14. Craig CL, Cameron C, Russell SJ, Beaulieu A. Increasing physical activity: building a supportive recreation and sport system [Internet]. Ottawa (ON): Canadian Fitness and Lifestyle Research Institute: 2001 [cited 2013 Jul 8]. Available from: http://www .cflri.ca/media/node/426/files/99pam.pdf

15. National Sporting Goods Association. 2010 sports participation: ranked by total participation [Internet]. Mount Prospect (IL): NSGA; 2010 [cited 2013 Apr 16]. Available from: http://www.nsga.org/files/public/2010 Participation_Ranked_by_TotalParticipation -4Web.pdf

16. National Sporting Goods Association. 2010 women's participation: Ranked by total female participation [Internet]. Mount Prospect (IL): NSGA; 2010 [cited 2013 Apr 16]. Available from: http://www.nsga.org/files/public/2010 Women'sParticipation-RankedbyTotalFemale Participation_4Web.pdf

17. Leslie E, Kremer P, Toumbourou JW, Williams JW. Gender differences in personal, social and environmental influences on active travel to and from school for Australian adolescents. J Sci Med Sport. 2010;13:597-601. doi:10.1016/j.jsams.2010 .04 .004

18. Morrongiello BA, Rennie H. Why do boys engage in more risk taking than girls? The role of attributions, beliefs, and risk appraisals. J Pediatr Psychol. 1998;23:33-43. 
19. Hassan I, Dorani BJ. Rollerblading and skateboarding injuries in children in northeast England. J Accid Emerg Med. 1999; 16:348-50.

20. National Sporting Goods Association. Tenyear history of sports participation [Internet]. Mount Prospect (IL): NSGA; 2010. Available from: http://www.nsga.org/files/public /Ten-Year_History_of_Sports_Participation _4web_100521.pdf

21. Russell K, Hagel B, Francescutti LH. The effect of wrist guards on wrist and arm injuries among snowboarders: a systematic review. Clin J Sport Med. 2007;17:145-50. doi:10.1097/JSM.0b013e31803f901b

22. Schieber RA, Branche-Dorsey CM, Ryan GW, Rutherford Jr. GW, Stevens JA, O’Neil J. Risk factors for injuries from in-line skating and the effectiveness of safety gear. N Engl J Med. 1996;335:1630-5.

23. Committee on Injury and Poison Prevention; American Academy of Pediatrics. Skateboard and scooter injuries. Pediatrics 2002;109: 542-3.

24. Broglio SP, Puetz TW. The effect of sport concussion on neurocognitive function, self-report symptoms and postural control: a meta-analysis. Sports Med. 2008;38: 53-67.

25. Yeates KO. Mild traumatic brain injury and postconcussive symptoms in children and adolescents. J Int Neuropsychol Soc. 2010; 16:953-60. doi:10.1017/S1355617710000 986

26. Kang J, Hagel B, Emery CA, Senger T, Meeuwisse W. Assessing the representativeness of Canadian Hospitals Injury Reporting and Prevention Programme (CHIRPP) sport and recreational injury data in Calgary, Canada. Int J Inj Contr Saf Promot. 2013;20:19-26.

27. Pickett W, Brison RJ, Mackenzie SG, et al. Youth injury data in the Canadian Hospitals Injury Reporting and Prevention Program: do they represent the Canadian experience? Inj Prev. 2000;6:9-15.

28. Gittelman MA, Pomerantz WJ, Fitzgerald MR, Williams K. Injury prevention in the emergency department: a caregiver's perspective. Pediatr Emerg Care. 2008;24:5248. doi:10.1097/PEC.0b013e318180fddd
29. Fernandez WG, Winter MR, Mitchell PM, et al. Six-month follow-up of a brief intervention on self-reported safety belt use among emergency department patients. Acad Emerg Med. 2009;16:1221-4. doi:10.1111/j.15532712.2009.00491.x

30. Bishai D. Contracting with children and helmet distribution in the emergency department to improve bicycle helmet use. Acad Emerg Med. 2003;10:1371-7. doi: 10.1197/S1069-6563(03)00540-2

31. Gittelman MA, Pomerantz WJ, Frey LK. Use of a safety resource center in a pediatric emergency department. Pediatr Emerg Care. 2009;25:429-33. doi:10.1097/PEC. 0b013e3181ab77e0 